ISSN:1991-8178
EISSN: $2309-8414$
DOI: $10.22587 /$ ajbas.2017.11.15.14
Journal home page: www.ajbasweb.com

\title{
The Relationship between the Employees and Organizational Management on the Tourism Satisfactory
}

\author{
${ }^{1}$ Annis Nobahar, ${ }^{2}$ Rahmat Azam Mustafa \\ ${ }^{1}$ Master Student, Universiti Sains Malaysia, Tourism Development School of Housing, Building and Planning, Penang, Malaysia \\ ${ }^{2}$ Dr., Universiti Sains Malaysia, Tourism Development School of Housing, Building and Planning, Penang, Malaysia.
}

\section{Address For Correspondence:}

Annis Nobahar, Master Student, Universiti Sains Malaysia, Tourism Development School of Housing, Building and Planning, Penang, Malaysia.

Email: anis.pars@gmail.com

\section{A RT I CLE INFO}

Article history:

Received 12 October 2017

Accepted 22 December 2017

Available online 31 December 2017

Keywords:

Employees, Organizational Management, Economic, Tourism Industry, Tourism Satisfactory

\begin{abstract}
A B S T R A C T
BACKGROUND: The organizational management defines as a common management style for new businesses. The organizational method can be defined as managers to break down the entire operation of a department into several phases. OBJECTIVE: The needs for organizational arises from an effective management which is required for the better coordination among various departments. On the other hand, employees accomplish tasks within the stipulated time frame as a result of effective organization management. The organization management together with the employees of the system should lead the entire system into a peaceful and positive workplace. All parameters together should made an attempt to make the satisfactory of the tourism of a country or of a city. The current research made an attempt to make a view of the organizational management, satisfactory of the tourism, and investigating the relationship between them based on the common theory of need with the help of employees satisfactory used for satisfaction of the tourism. RESULTS: To do so, individual interviews were conducted with 11 employees from different sector of the tourism industry containing the first section of 22 work motive statements, while the second section contained 10 questions on demographics and current work information. Data analyzing used to process the survey results included descriptive statistics, confirmatory factor analysis (CFA), and structural equation modeling (SEM). CONCLUSION: The major outcome of this study is the newly developed work motive measurement instrument. The results also showed that females made up more satisfy than male participants into a 96 percent of the respondents were those are 26 or younger.
\end{abstract}

\section{INTRODUCTION}

The organizational management or the leadership function of the organizational management structure can be overlooked by some businesses or industries. However, this aspect is vitally important to successful management. An ideal leader is a person who has the ability to connect with employees and others who are instrumental in facilitating the goals of the organization. Leaders serve a purpose other than simply creating and managing a plan. In addition to the ability to relate positively to other employees, an ideal leader also possesses qualities of integrity, drive and industry knowledge; and is confident in their leadership missions. In the contrast in the literature the employees define as an individual who works part-time or full-time under a contract of employment, whether oral or written, express or implied, and has recognized rights and duties. Also called worker. In the tourism industry the relationship between the organizational management and employees has an important impact on the tourism industry and in particular into the tourism satisfactory rate. However this will lead to some employee's problem. The problem of employee commitment in relation to full-time and part-time work has not been fully explored and therefore requires detailed study and analysis (Chung-Chieh Lee, Chih-Jen

Open Access Journal

Published BY AENSI Publication

(C) 2017 AENSI Publisher All rights reserved

This work is licensed under the Creative Commons Attribution International License (CC BY). http://creativecommons.org/licenses/by/4.0/

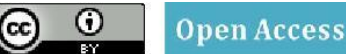

To Cite This Article: Annis Nobahar, Rahmat Azam Mustafa, The Relationship between the Employees and Organizational Management on the Tourism Satisfactory. Aust. J. Basic \& Appl. Sci., 11(15): 98-103, 2017 
Chen, 2013). This study tries to fill the gap in the literature using more significant data to the subject. Morrison \& Robinson believe that without motivation, the workers feel short-changed; they feel as if they have nothing much to work for (Morrison \& Robinson, 2016). To define the problem statement more practically, (Schermerhorn, Hunt, and Osborn 2013), among a range of issues, more focus made on questions covering leadership, and the work commitment of employees in the tourism industry. They assert that part-time work is becoming more popular, despite its controversial work arrangements. (Franek and Vecera, 2015) indicate employee satisfaction becomes diversified when one group of people starts to desire differently from what another group wants. Changes in workforce demographics have played a major role with fueling interests on diversity in the hotel industry. Just knowing employees personally within the organization may not be enough for hoteliers to appropriately manage them. Understanding factors that play important roles in work environments are needed to foster diversity in hotel organizations as an example.

However, there is a big gap between what employees say is important to what they believe is

achievable in the organizational system.

Fig. 0-1 shows the above mentioned gap.

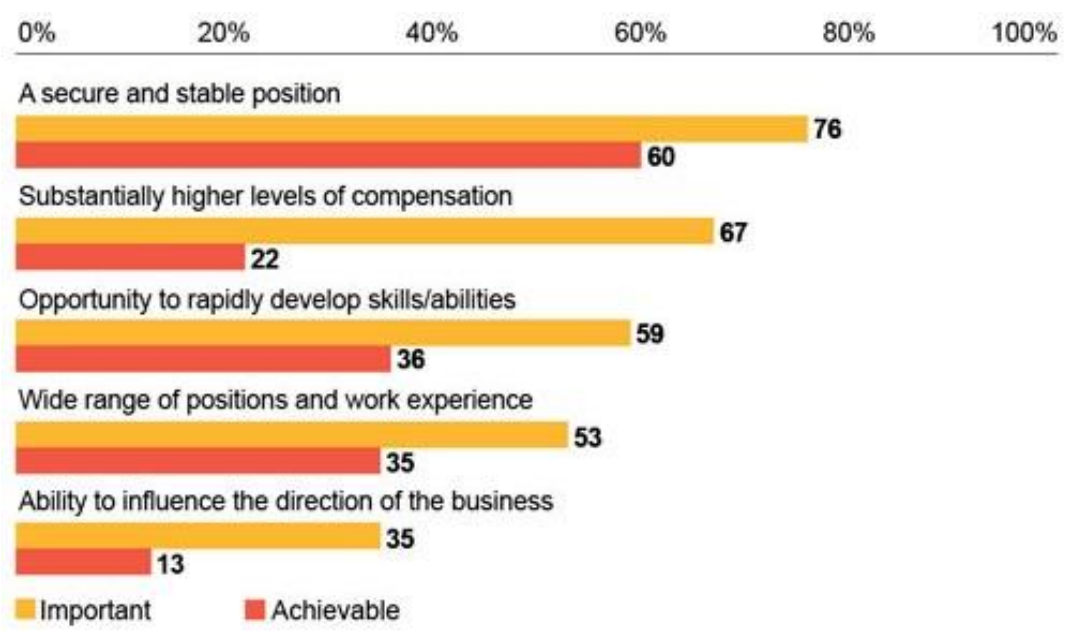

Fig. 0-1: Gap between What Employees Say is Important to What They Believe is Achievable in the Organizational System

In the same way, the cost to the organizational system to the value of an employee has an important rate $($ see

Fig. 0-2). The figure shows that the employee development has a direct influence on the management organizational and economical growth of the system. The employee benefits to the organizational system begin just after the training finishes. 


\section{COST TO VALUE OF AN EMPLOYEE}

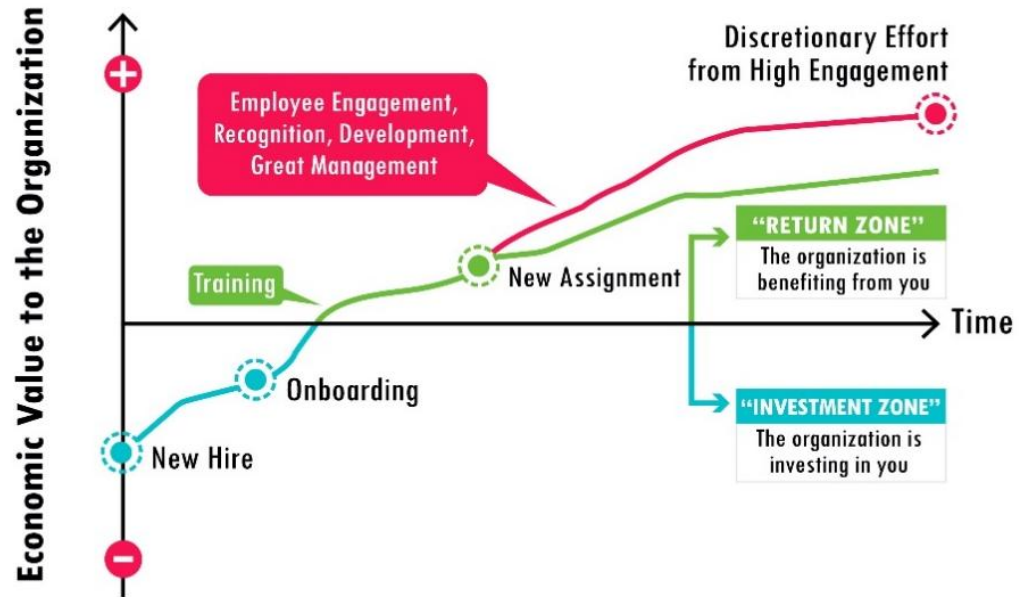

Fig. 0-2: The Benefits Growth of an Employees to the Employers.

\section{Chart of Ordinal data}

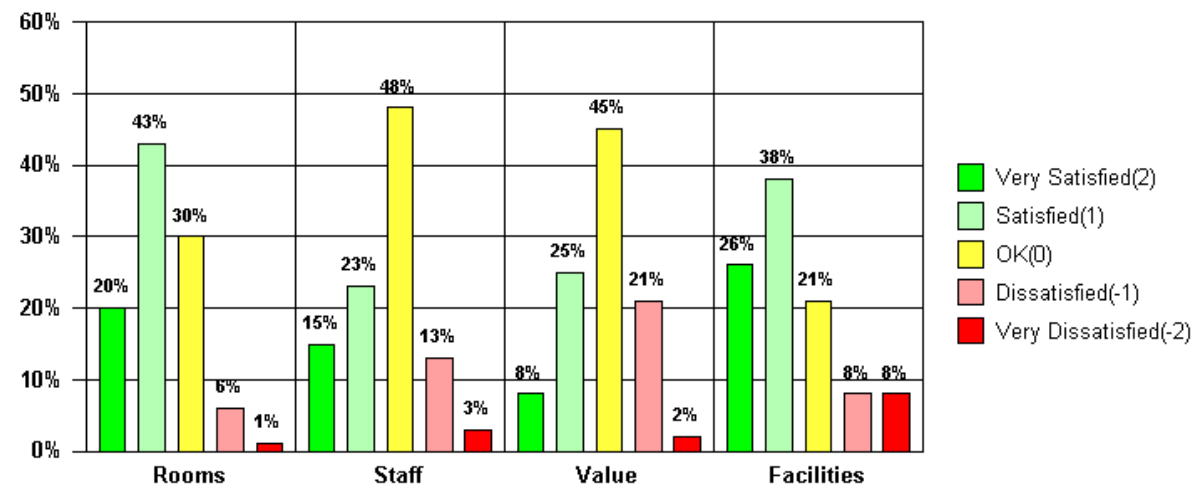

Fig. 0-3: Ordinal Data on the Satisfactory of the Visitors.

The visitor's satisfactory rates is shown in

Fig. $\mathbf{0 - 3}$. The figure shows that the staff, the value for money and the room facilities has a numerous value to the satisfactory of the hotel organizational.

\section{The Organizational System, the Employee and the Visitors Satisfactory:}

Understanding employees' motives for working is important to ensure the congruence between individuals' work values and an organization's culture and goals. In this research, the investigation of the relationship between employees' work motives and job satisfaction together with tourism satisfactory will be deeply discussed. To do so, first, in-depth interviews with hospitality employees provided information about their motivations for work in the current industry. Next, a questionnaire regarding employees' work motives, job satisfaction, organizational commitment, and organizational citizenship behaviors was developed and used to explore relationships among the four study variables.

The theoretical framework of the above mentioned relationship is given in

Fig. 0-1. The figure illustrates the first, six constructs are the need for achievement, need for power, and need for affiliation, along with work motives, citizenship behaviors, and job satisfaction. Second, seven constructs are the work itself, pay, promotion, supervision, and co-workers, along with job satisfaction and organizational commitment. Third, five constructs are affective organizational commitment, continuance organizational commitment, and normative organizational commitment, along with organizational commitment and citizenship behaviors. Fourth, three constructs are organizational citizenship behaviors towards the organizational system. 


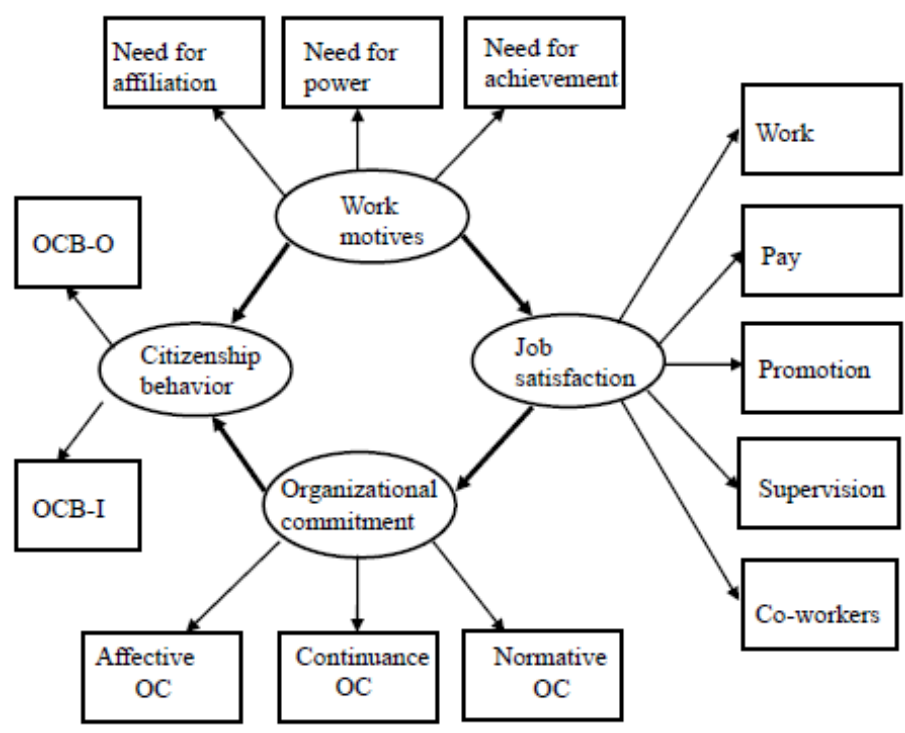

Fig. 0-1: Modal Conceptual.

Fig. 0-2 displays the relationship between the organizational system, and the employee's satisfactory. The model suggested that hospitality employees' motivations for work are importantly and positively related to their subsequent work behaviors and work attitudes. The present study consists of both qualitative and quantitative methods. First, a qualitative method was used to explore employees' work motivations and their founding were then used to develop an instrument appropriate for measuring employees' work motives in the hospitality industry. In-depth individual interviews, hospitality employees were explored and the results were identified. Next, a questionnaire incorporating scales from the interview results and the literature was developed; a cross sectional survey design was used to investigate employees, job satisfaction, organizational commitment, and organizational citizenship behaviors. Based on Ambrose \& Kulik, 1999 theory the following sections describe the different impact phases. 


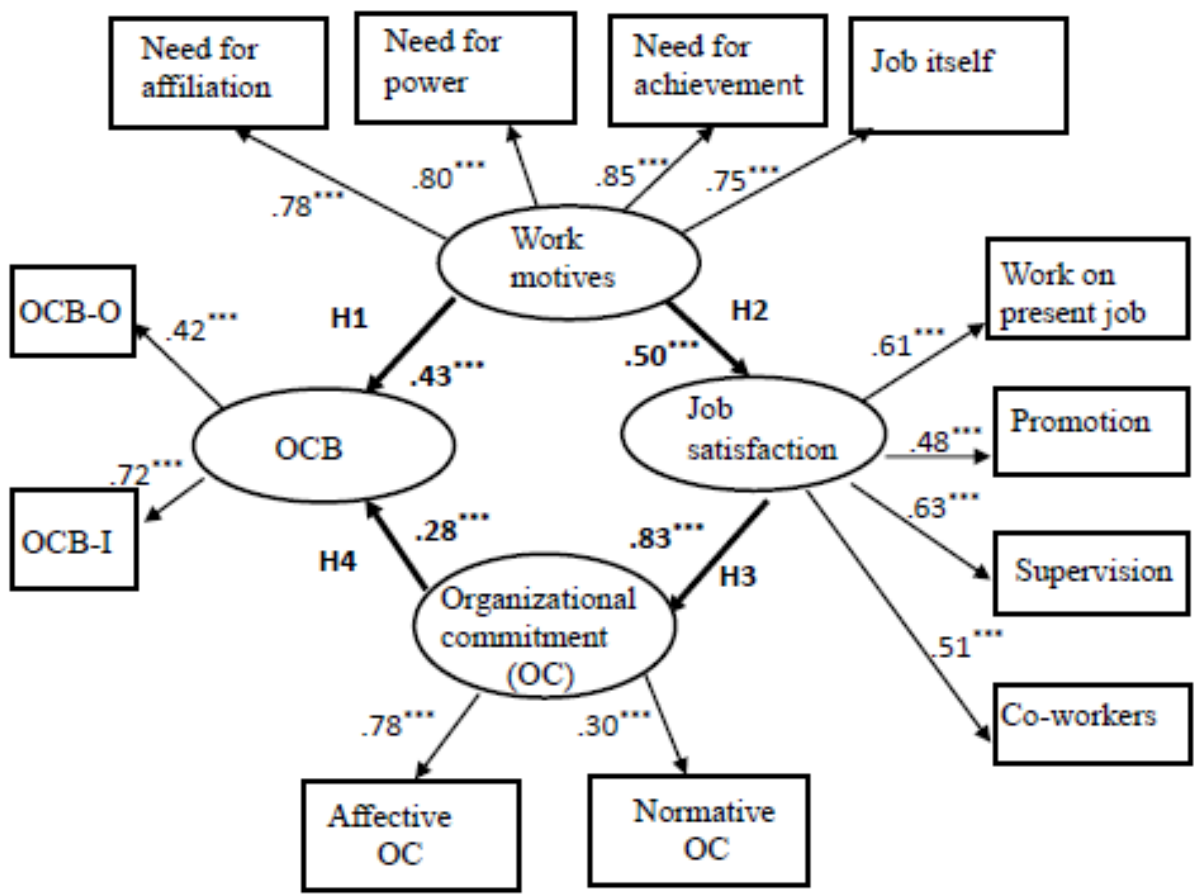

Note: $\mathrm{OC}=$ organizational commitment $\mathrm{OCB}=$ organizational citizenship behavior; $\mathrm{OCB}-\mathrm{O}=$ organizational citizenship behavior toward organization; OCB-I = organizational citizenship behavior toward internal customers.

$* * * p<.001$

Fig. 0-2: The Relationship between the Organizational System, and the Employee Satisfactory.

On the contrast, there are some other impacts that is counted by the system itself such as; Environmental impacts that affect the carrying capacity of the area, vegetation, air quality, bodies of water, the water table, wildlife, and natural phenomena. Social and cultural impacts associated with interactions between peoples and culture background, attitudes and behaviors, and relationships to material goods. The introduction of tourists to sensitive areas can be detrimental, cause a loss of culture, or, alternatively, contribute to the preservation of culture and cultural sites through increased resources. Economic impacts usually seen as positive, contributing to employment, better services, and social stability. Yet these impacts can also contribute to high living costs within the community, pushing local business out of the areas, and raising costs for locals.

\section{Case Study:}

The developed work motivations scale was tested by surveying the employees with student status. Students, those under 25 years old, and part-timers make up the majority of the workforce in the European community restaurant industry. In addition, according to a statistical report from the European Community Bureau, "uncertain noneconomic reason" was the most common cause employees gave for choosing a part-time job, while being in school and "in training" was the second most common cause. Considering the characteristics of the hospitality workforce, hospitality employees with student status were therefore selected as an appropriate sample for this present survey.

A self-administered paper questionnaire was used to test the developed work motive scale. The questionnaire consisted of two sections. The first section contained 22 work motive statements, while the second section contained 10 questions on demographics and current work information. In the first section, participants were asked to indicate the extent of their agreement with each of 22 statements using a seven-point Likert-type scale ranging from 7 (strongly agree) to 1 (strongly disagree). The questionnaire was printed in booklet form and color-coded to reflect the different participant locations. A pilot test was conducted with hospitality employees who were also students $(n=94)$ prior to the final data collection. In addition, to maintain data consistency, pilot study data were excluded from the final data analysis. Data was analyzed using Statistical Package for the Social Sciences (SPSS 20). First, descriptive statistics were computed. Next, reliability as a measure of internal consistency (Cronbach's alpha) was calculated. Confirmatory Factor Analysis was conducted using MPlus 6.0 to test the validity of the measurement scale.

\section{RESULTS AND DISCUSSION}


The major outcome of this study is the newly developed work motive measurement instrument. The instrument was designed to measure work motivations specific to the hospitality employees. Through a mixed methods research design, a work motive scale containing four factors, was developed and demonstrated to be valid and reliable. The results authenticated the use of a mixed methods approach for quantitative instrument development (Creswell and Clark, 2007).

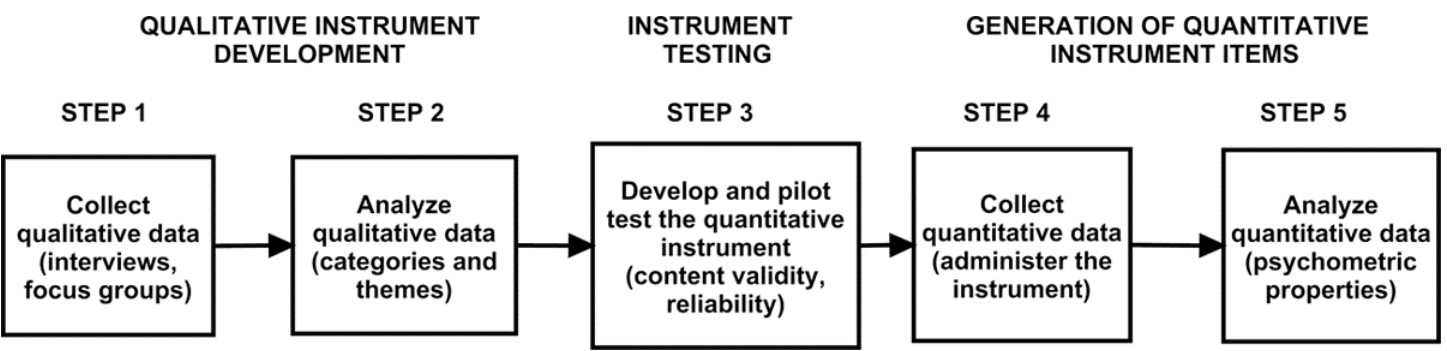

Fig. 6: The Qualitative Instrument Development Steps.

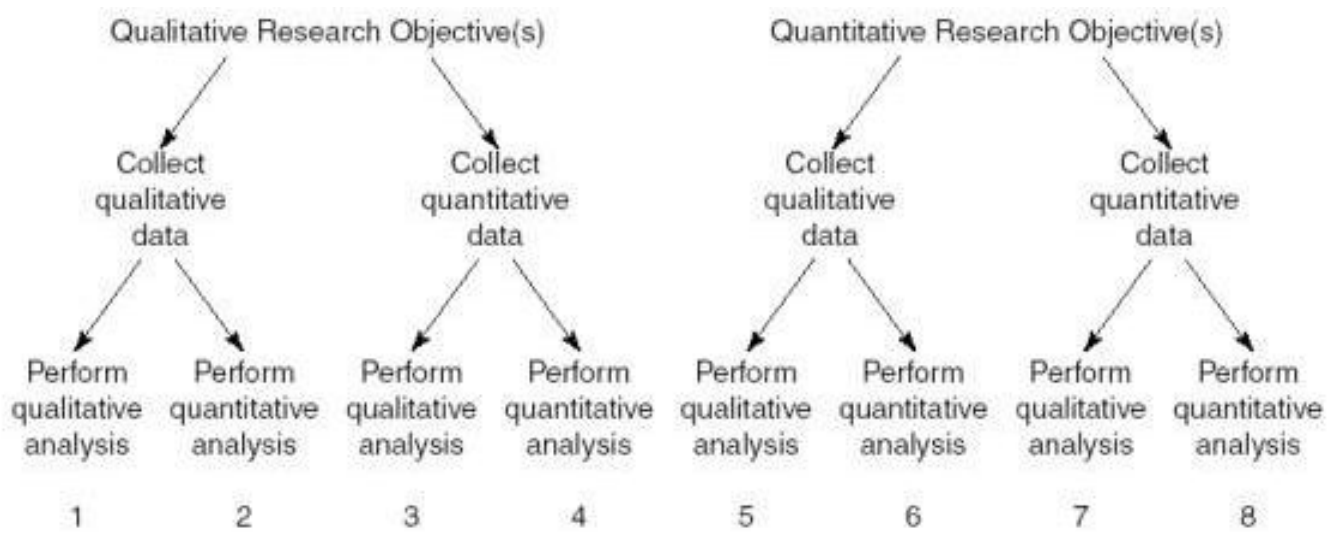

Fig. 7: The Qualitative Research Objectives.

The findings of this present study provide perspectives on why individuals seek employment in the hospitality industry. The respondents comprised $76.5 \%$ females and $23.5 \%$ males. The average age of the respondents was 22 years old; age categories were as follows: 18 to 20 years old (27.7\%), 21 to 23 years old (55.4\%), 24 to 26 years old $(12.7 \%)$, and over 26 years old $(4.1 \%)$. Most $(74 \%)$ of the respondents were majoring in Hospitality Management. Classification data showed that 20 (5.2\%) respondents were freshmen, 62 $(16.0 \%)$ were sophomores, $132(34.0 \%)$ were juniors, $149(38.4 \%)$ were seniors, and $25(6.4 \%)$ were graduate students. Almost half (45.7\%) of the respondents worked/ had worked at restaurants, $19.2 \%$ at hotels, $11.4 \%$ at university dining rooms, and $23.7 \%$ at some other place related to either the related industry or the foodservice industry. Given that the largest percentage of the interviewers worked at restaurants, it is not surprising that the areas in which respondents worked were front-of-the house $(36.2 \%)$ or back-of-the house $(8.4 \%)$; others worked at the front desk $(16.4 \%)$ and a small percentage worked in housekeeping (1.0\%). Over half of the respondents worked part-time $(77.0 \%)$ and at their current place of employment for one year or less (60.0\%). Approximately $50.0 \%$ of the respondents had worked in the hospitality industry for two years or less, while 50.4\% had worked there for three years or less. Hence in collusion.

\section{Conclusion:}

The paper conclude that tourism has various consequences, which are influenced by a large number of factors, especially the ability and willingness of the community to accept changes (Beeton, 2006:21). For some communities, tourism is one of the few options for economic survival. For others tourism is a combination of positive and negative factors (the most common situation). Finally, there are communities where tourism has generated a large number of negative externalities, for which the population was not ready. To avoid these unpleasant situations planning and strict control by the community and authorities are needed (Statzu and Strazzera, 2011:58; Roberts and Hall 2001:55). Goeldner and Ritchie (2012:25) believe that the challenge for the tourism industry is obtaining benefits that will outweigh the costs, and taking measures to 505 mitigate negative effects. "Tourism development should be part of an economic development and must be done in a manner that is sustainable." 


\section{REFERENCES}

Bowling Green State University. 2012. Job Descriptive Index [Web page]. Retrieved from http://www.bgsu.edu/departments/psych/io/jdi/page54706.html

Cho, S., M.M. Johanson, 2008. Organizational citizenship behavior and employee performance: a moderating effect of work status in restaurant employees. Journal of Hospitality \& Tourism Research. 32(3): 307-326.

Chung-Chieh, L., C.J. Chen, 2013. The relationship between employee commitment and job attitude and its effect on service quality in the tourism industry. American Journal of Industrial and Business Management, 3(2): 196.

Creswell, J.W., 2003. Research design: Qualitative, quantitative, and mixed methods approaches. Thousand Oaks, CA: Sage Publications, Inc.

Dilman, D.A., J.D. Smyth, L.M. Christian, 2009. Internet, mail, and mixed-mode surveys: The tailored design method. New York: John Wiley \& Sons, Inc.

Franek, M., J. Vecera, 2008Personal characteristic and job satisfaction. Ekonomie A Management, 63-76. Retrieved on 5.04.2014 from www.ekonomie-management.

Lickorish, L. and C. Jenkins, 1997. An introduction to tourism, Oxford: Butterworth-Heinemann.

McClelland, D.C., 1985. How motives, skills, and values determine what people do. American Psychologist, 40: 812-825.

McClelland, D.C., J. Atkinson, R. Clark, E. Lowell, 1976. The achievement motive. New York: Irvington.

National Restaurant Association., 2013. Jobs \& Careers Powerhouse. http://www.restaurant.org/IndustryImpact/Employing-America/Jobs-Careers-P owerhouse (retrieved 06.19.13).

Podsakoff, P.M., S.B. MacKenzie, J.B. Paine, D.G. Bachrach, 2000. Organizational citizenship behaviors: a critical review of the theoretical and empirical literature and suggestions for future research. Journal of Management, 26(3): 513-563.

Poulston, J., 2008. Hospitality workplace problems and poor training: a close relationship. International Journal of Contemporary Hospitality Management, 20(4): 412-427.

Robinson, S.L., E.W. Morrison, 2000. The development of psychological contract breach and violation: A longitudinal study. Journal of organizational Behavior, pp: 525-546.

Schermerhorn, Hunt, and Osborn, 2013. Cultural revolution-just what multinational companies need: A case of GE. Journal of Business Case Studies (Online), 9(1): 59.

Shenton, A.K., 2004. Strategies for ensuring trustworthiness in qualitative research projects. Education for Information, 22: 63-75. 